\title{
Foreword
}

\section{Ian Christie}

At the time of the Rio de Janeiro Summit on Environment and Development in 1992, the then US President George Bush Senior declared that whatever else was on the agenda, the American lifestyle was not up for negotiation. Although few other heads of state and political leaders in the rich world have made such uncompromising remarks about the untouchability of their domestic mode of consumerism, there has been huge reluctance among politicians and policy makers to contemplate 'lifestyle change' and any notion of limits to consumption in devising strategies to meet the enormous challenges posed by the risk of climate disruption, ecological breakdowns and depletion of key resources.

The reasons for this are plain enough. First, the economy and culture of mass consumer affluence have been established in the West for half a century or more, and have been felt to 'deliver the goods' with unprecedented success. The idea that this enormously productive system might run up against ecological limits is deeply unwelcome, and one that is bound to be resisted by many. Policy makers and many citizens hold to a picture of the world, a seemingly robust one, in which new technologies will always come to the rescue, as they have flowed in profusion throughout living memory.

Secondly, democratic political competition has been geared for decades to the idea that living standards and consumption can continue to rise indefinitely. There is no mainstream vehicle or ideology for articulation of any alternative 'frame' or paradigm for economic and social life. Thirdly, the UK and many parts of the West are now a thoroughly liberalized set of polities and economies. The 1960s' cultural revolutions have led to a widespread, if still contested, pattern of social liberalism; the 1980s' economic revival of liberalism led to a similarly widespread and still more contested deregulatory paradigm in policy making and governance. In this world, individual choice in lifestyle is supreme, subject only to restraints established in law. At worst, this has led to a hollowing-out of the very idea of the public good and of common values and standards that trump individual choices in the marketplace. It has also combined with other 
'atomizing' forces in society to weaken the institutions, civil associations and everyday practices of cooperation at local level between the state and the individual. That too makes for a barrier to political action: if environmental policy pressures demand 'lifestyle change', then there seems to be little else to do other than set up a one-sided process of exhortation between state and individuals, typically via information campaigns that have little effect because they exist in a social vacuum.

This is an unpromising context for promoting changes in behaviour on a societal scale. But the nature of the ecological challenges at hand tells us that precisely this is what is needed. Why? To see the fundamental reason, we need to consider the famous 'Sustainability Equation' published in 1974 by Paul Ehrlich and John Holdren, $I=P A T$. Here $I$ is ecological impact of development, which in turn is the product of three factors - Population, Affluence (i.e. levels of consumption) and Technology (efficiency of production and consumption). We face a rising global population for sure; rising consumption demands for sure; and possible gains in technology that can boost production of key resources (food) and improve efficiencies (energy and material reduction, recycling and reuse). The rise in population and consumption that is in store to the middle of the century is so great that in order to reduce our already unsustainable collective impact on the Earth's climate system, resources, sinks and biodiversity, a near-incredible continuous improvement in resource efficiency would need to take place in coming decades. (For more on this, see Tim Jackson's masterly Prosperity without Growth, Earthscan, 2009.) Now, it may be that such gains can be made and that 'rescue technologies' will arrive. But no-one can count on this: the lesson of recent decades is that advances in marginal efficiency of key technologies (vehicle engines, for instance) are overwhelmed by the scale of increase in consumption. There is no reason to suppose this problem will disappear; and every reason to suppose it will get worse as population grows and with it the justifiable demands of the global poor for better lives and more consumption.

Technological innovation is crucial to the transition to a low carbon economy and sustainable patterns of development, but while necessary it is far from sufficient. Population growth has slowed and global population may well stabilize in the middle of the century, but we want that to happen through peaceful and gradual social change, not to be precipitated by ecological disruption. So we are left with the third term in the Sustainability Equation - consumption - when it comes to making sure of a successful transition from unsustainable and fossil-fuel-dependent societies. Large parts of the world need to be able to consume more, for reasons of equity, justice and poverty reduction; so the rich world needs to consume differently, and with far less impact, to allow room for the poor to raise their 
quality of life and to allow for ecological recovery. This means consuming some things differently; consuming some new services and products; substituting some for others; and in some respects - such as aviation and car use - doing with less than we have become accustomed to. All that adds up to 'behaviour change' - and to add to the complexity, it must be negotiated and designed to ensure that social inequalities are not worsened. The moment limits to consumption are invoked, attention falls on the existing distribution of opportunity and resource use. Lifestyle change is a distributional issue as well as a problem of motivating changes in behaviour, attitudes and values.

This all helps explain the reluctance of politicians and policy makers to speak plainly about the inescapable need for changes in consumption, including real reductions in some carbon-intensive activities. However, the weight of evidence about actual and possible climate change, and the complexity and time-lags involved in radical changes to the supply side of energy systems, mean that this reluctance has been diminished. There is no choice but to confront lifestyle change and the question of how to influence behaviour, attitudes and values.

What has become apparent is that systematic knowledge is lacking: policy making has been based on hunches and rough working assumptions about behaviour, or on deeply flawed models of agency such as the individualist rational choice paradigm in economics. So there is now a small but vital 'industry' working on behaviour change issues in relation to environment and sustainability across Whitehall, in public agencies, in local government, all hungry for robust evidence and guidance from academic research.

The University of Surrey's RESOLVE programme on lifestyles, consumption and low carbon living is at the leading edge of academic research, with many emerging results that are highly relevant to policy makers. This volume provides many illustrations of the valuable insights emerging from RESOLVE and other programmes and projects in the UK and beyond. One of the major themes of social scientific research in this field concerns the implications of the fundamental insight that a great deal of what appears to be autonomous 'individual choice' is socially mediated and 'constructed'. Our desires are our own, but they are shaped and influenced by social context - what our peers deem desirable, what role models and other influencers are doing and saying, what social norms tell us is acceptable, what we feel we need to want and be like in order to be accepted by others and make a respectable place for ourselves in our social worlds. A key implication, supported by many findings, is that when we change our behaviour we do it as a result of, and in tandem with, wider socially validated changes. It is far easier for an individual to change 
consumption choices and behaviour if the surrounding social environment helps her to do so, validates the choice, does not make her feel as if she is 'standing out', and enables her to make changes along with a suitably large and convincing body of peers. In other words, individual change is made much more likely and easy if it is part of a collective shift. Social incentives help make new individual behaviour possible.

This is important because it helps us understand why the prevailing policy model for inducing behaviour change is so weak. Governments and agencies have often assumed that provision of information will lead to individuals rethinking what they do, and making a change. In practice, information may be necessary but is invariably insufficient. People need to make changes to lifestyles via shifts in social norms and incentives that help move whole sections of society. This leads us to focus afresh on old and new forms of association and social interaction lying at levels between the state and the individual, for it is here that the influence of peers, crowds and role models may be most powerful. It is also here that old lessons about the importance of small-scale, 'intermediate' civil associations in social life and changes in norms and behaviour may need to be relearned and applied in new settings. For the social and economic revolutions of the 1960s and 1980s have been damaging to many such institutions (political parties, trade unions, churches, voluntary bodies, neighbourhood organizations and informal local voluntary arrangements between households).

A great deal of effort is now being made to think through how we might reinvigorate these intermediate organizations of civic cooperation and innovate with existing ones and new forms of association. The widespread political move to rethink 'localism' has been born of disillusionment with central bureaucracies and excessive control over local governance, but it could have a positive dimension in relation to sustainability. Central government is neither trusted nor uniquely capable when it comes to promoting behaviour change for sustainable living, but there could be a renewed role for local government and civil institutions at local level in this field. Local councils are closer to the citizen and are certainly more efficient at 'delivery' than much of central government has been. And there is a hunger for new forms of 'community spirit' and cooperation, as a reaction against excessive and atomising individualism and 'marketization' over the past generation, and as a key part of the search by many people for ways to reduce their impact on the environment and contribute to sustainable living for all. This brings together innovation in old forms of association - such as projects led by many people in faith communities, increasingly concerned with environmental action; and innovation in new vehicles for cooperation and collective behaviour change, such as the fastgrowing Transition Town movement. 
These are exciting developments, illuminated and assisted by leading academic research and thinking of the kind on display in this volume. Few aspects of the transition to sustainability are more important than the search for effective means of enabling behaviour change, innovation and cooperation in local communities. This collection is a hugely valuable contribution to our understanding, and to the work of practitioners and policy makers alike. 